\title{
Membranous nephropathy associated with malignant pleural mesothelioma in an adult patient: A case report
}

\author{
XINYU PU, YANNA DOU, DONG LIU, SHAN LU, SONGXIA QUAN, \\ XIAOXUE ZHANG, SHUANG MA and ZHANZHENG ZHAO
}

Department of Nephrology, The First Affiliated Hospital of Zhengzhou University, Zhengzhou, Henan 450052, P.R. China

Received January 29, 2016; Accepted June 13, 2016

DOI: $10.3892 / \mathrm{mco} .2016 .976$

\begin{abstract}
A 23-year-old man presented to our hospital with membranous nephropathy and received a detailed examination, including pleural biopsy, due to a feeling of chest oppression. The result of the pleural biopsy was malignant pleural mesothelioma. However, the patient did not have a history of asbestos or tobacco exposure. A review of the English literature identified only 7 reported cases of concomitant malignant mesothelioma and nephrotic syndrome. Furthermore, among the 7 cases reviewed, 6 had a history of asbestos exposure, 1 had a history of prolonged tobacco exposure and in only 1 case the renal pathology results revealed the presence of membranous nephropathy.
\end{abstract}

\section{Introduction}

Malignant pleural mesothelioma (MPM) is a high-grade malignancy of the chest that develops from mesothelial cells of the serosal membranes. The incidence of MPM is low and differs among different countries worldwide, from 7/million inhabitants in Japan to 40/million inhabitants in Australia annually (1). MPM is closely associated with a history of asbestos exposure. The major clinical manifestations of MPM are pleural effusion, chest pain, dyspnea and emaciation. If the kidneys are invaded, the patients may present with anasarca and/or renal insufficiency. However, the clinical manifestations of MPM are usually non-specific and insidious and should not be used alone as diagnostic criteria. The diagnosis of MPM should be based on immunohistochemical examination of the pleural tissue. The specific and sensitive positive markers include anti-calretinin (CR), anti-epithelial membrane antigen, anti-cytokeratin (CK) 5/6, anti-D2-40 (podoplanin), anti-mesothelin and, particularly, anti-Wilms tumour antigen-1. Other makers are of negative diagnostic value, including

Correspondence to: Professor Zhanzheng Zhao, Department of Nephrology, The First Affiliated Hospital of Zhengzhou University, 1 Jianshe Road, Zhengzhou, Henan 450052, P.R. China

E-mail: zzzdoctor@139.com; zhanzhengzhao@zzu.edu.cn

Key words: nephrotic syndrome, membranous nephropathy, malignant pleural mesothelioma
anti-Ber-EP4, anti-thyroid transcription factor-1 (TTF-1) and monoclonal anti-carcinoembryonic antigen (CEA) (1). The concept of paraneoplastic glomerulopathy was introduced by Galloway in 1922. Moreover, nephrotic syndrome secondary to malignant pleural mesothelioma is rarely reported. We herein report the case of a young man with a pleural mesothelial malignancy presenting subsequent to the manifestation of membranous nephropathy.

\section{Case report}

A 23-year-old man was admitted to our hospital on September 5, 2014. The chief complaint was edema of the lower limbs for 4 years, abdominal pain for 7 months and chest oppression for 5 months. The patient first noticed edema in the lower limbs 4 years prior and visited a local hospital. The laboratory data revealed positive urine protein (10.39 g/day) and hypoalbuminemia (serum albumin $15 \mathrm{~g} / \mathrm{l}$ ) and the patient was diagnosed with nephrotic syndrome. The renal biopsy confirmed the diagnosis of membranous nephropathy. Prednisone was administered $(60 \mathrm{mg} /$ day and gradually reduced). However, the patient reported that the edema reappeared several times. In addition, abdominal pain developed 7 months prior to admission. Laboratory examinations revealed a 24-h urine total protein of $5.28 \mathrm{~g}$ and a serum albumin level of $21 \mathrm{~g} / \mathrm{l}$. Thrombosis of the portal, splenic, superior mesenteric and renal veins and the inferior vena cava was identified on computed tomography (CT) and ultrasound scans performed in the local hospital. The patient underwent inferior vena cava filter implantation and infusion catheter-directed thrombolysis, and was initiated on tacrolimus (1 mg, twice per day). The pain was relieved and urine protein fluctuated between 0.68 and $13.6 \mathrm{~g} /$ day. The patient had poor appetite with a feeling of chest oppression that had developed 5 months prior and he was referred to our hospital. Physical examination revealed weakness and malnutrition. On palpation of the lymph nodes, the cervical and supraclavicular lymph nodes were found to be enlarged. The examination of the abdomen revealed distention and shifting dullness. In addition, there was edema of the lower limbs.

Laboratory results. The laboratory values were as follows: Hemoglobin 73 g/l, 24-h urine total protein 13.6 g, serum creatinine $88 \mu \mathrm{mol} / \mathrm{l}$, albumin $16.9 \mathrm{~g} / \mathrm{l}$, total cholesterol 
A
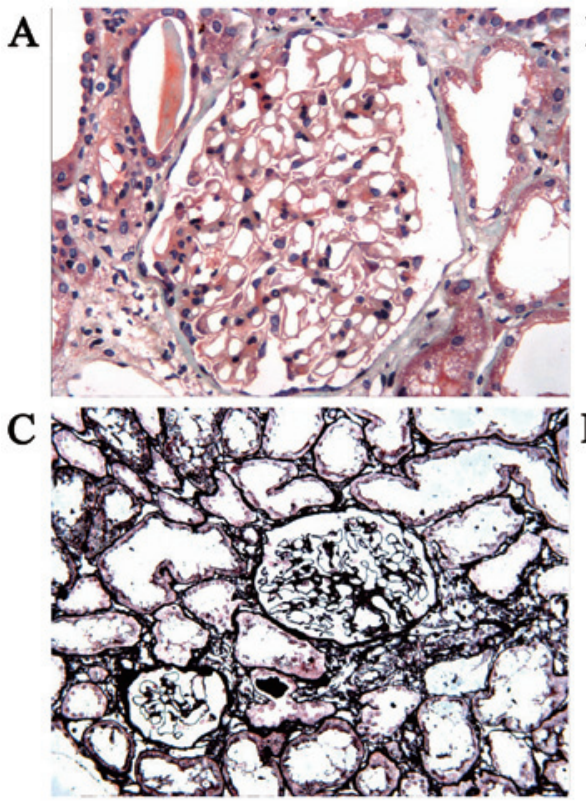
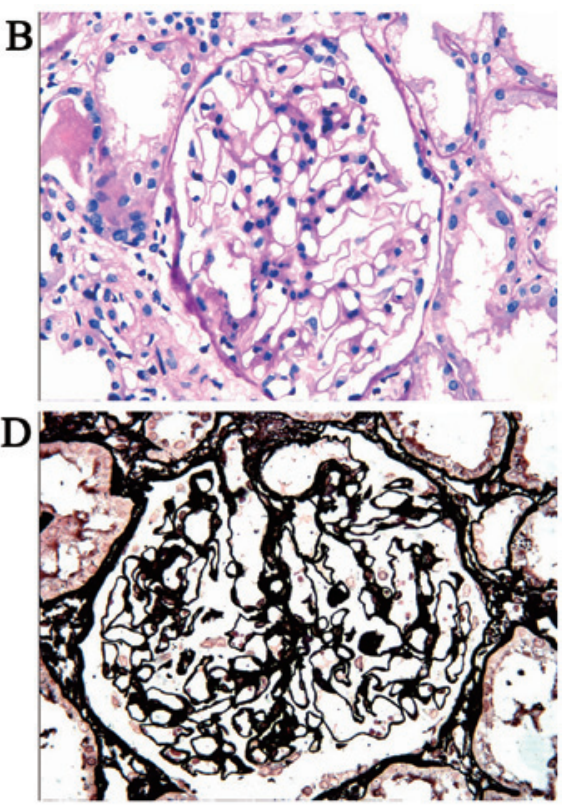

Figure 1. Pathology results of the renal tissue (light microscopy). (A) Glomerular subepithelial fuchsinophilic protein deposition (Masson's trichrome stain; magnification, x400). (B) Glomerular basement membrane thickening (Periodic acid-Schiff stain; magnification, x400). (C and D) Basement membrane thickening and stiff appearance. No spikes were identified (Periodic Schiff-Methenamine Silver stain; magnification, x200 and x400, respectively).
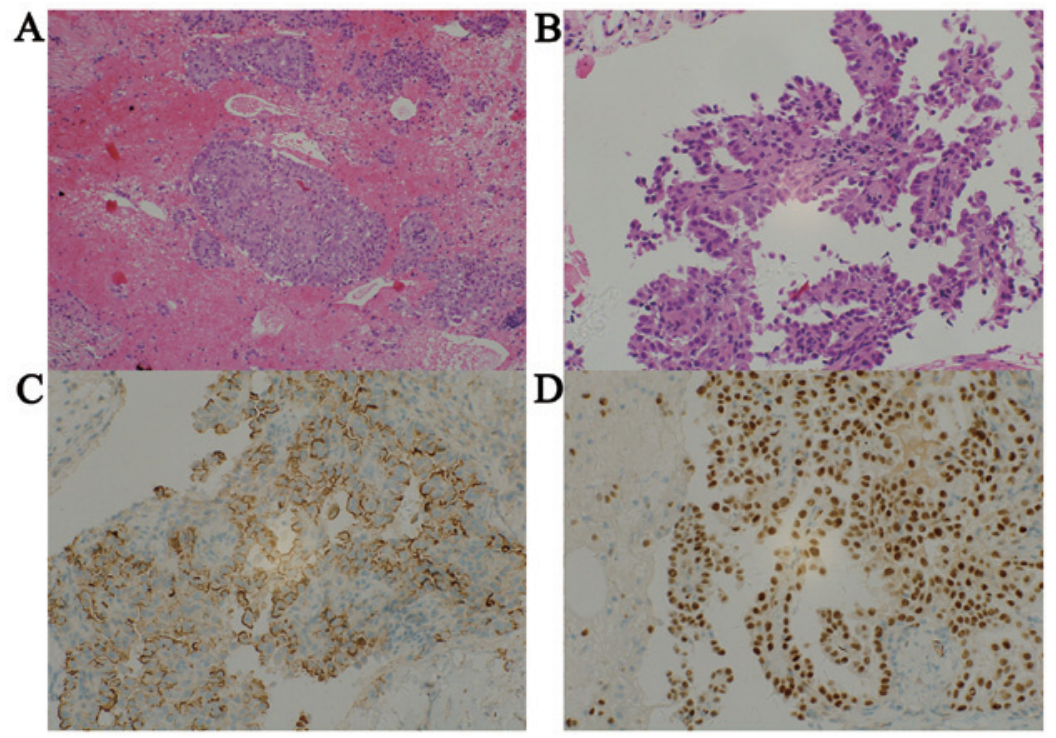

Figure 2. Pathology results of the pleural biopsy. (A and B) Papillary formations or sheets of epithelial cells were observed. Some of the nuclei had inclusion bodies (hematoxylin and eosin stain; magnification, x200 and x400, respectively). Immunohistochemical staining for (C) human bone marrow endothelial cell (magnification, $\mathrm{x} 400$ ) and (D) Wilms' tumour-1 (magnification, $\mathrm{x} 400$ ) is positive.

$6.9 \mathrm{mmol} / 1$ and triglycerides $2.17 \mathrm{mmol} / \mathrm{l}$. The cancer antigen 125 level was 4,190 U/ml. The anti-phospholipase A2 receptor (PLA2R) antibody was negative. Pneumonia and massive bilateral pleural effusion were identified on CT, whereas positron emission tomography-CT positron emission tomography-CT revealed enlarged lymph nodes with high uptake in the bilateral supraclavicular, peristernal, diaphragmatic, abdominal and retroperitoneal regions. Several areas of nodular pleural thickening and mass-like peritoneal thickening exhibiting high uptake were also observed. These are generally considered to be signs of inflammation, although they may occasionally indicate malignant tumors. Thus, lymph node biopsy was performed and revealed malignant cell invasion or metastasis.

Pathological examination of renal tissue sections was performed by the pathologist of our hospital. The immunofluorescent stains for immunoglobulin (Ig)G and $\operatorname{IgM}, \operatorname{Ig}$ A and C3 were negative. Under a light microscope, the glomeruli exhibited a mild hypercellularity of the mesangial cells and matrix, basement membrane thickening and a stiff appearance. However, no spikes were observed (Fig. 1).

On pleural biopsy examination, epithelial cells arranged in papillary formations or sheets were observed, with blood clots and fibrillar connective tissue. Some of the nuclei had inclusion 
Table I. Cases of nephrotic syndrome associated with malignant mesothelioma in the literature.

\begin{tabular}{|c|c|c|c|c|c|c|}
\hline Authors (Refs.) & $\begin{array}{l}\text { Age, } \\
\text { years }\end{array}$ & Gender & $\begin{array}{l}\text { Tumor } \\
\text { site }\end{array}$ & $\begin{array}{c}\text { Renal } \\
\text { biopsy result }\end{array}$ & $\begin{array}{l}\text { Main } \\
\text { treatment }\end{array}$ & Outcome \\
\hline Schroeter et al (3) & 68 & Male & Pleura & $\mathrm{MCN}$ & $\begin{array}{c}\text { Prednisone }+ \\
\text { cyclophosphamide }+ \\
\text { doxorubicin } \\
\text { hydrochloride }+ \\
\text { dacarbazine }\end{array}$ & Died \\
\hline Tanaka et al (4) & 77 & Male & Pleura & MPG & $\begin{array}{l}\text { Carboplatin }+ \\
\text { etoposide }+ \\
\text { glucocorticoid }\end{array}$ & Died \\
\hline Dogan et al (5) & 42 & Female & Pleura & Refused & Debulking surgery & Improvement \\
\hline Galesic et al (6) & 67 & Male & Pleura & $\mathrm{MN}$ & $\begin{array}{l}\text { Methylprednisolone } \\
\text { in respiratory } \\
\text { decompensation }\end{array}$ & Died \\
\hline Suzuki et al (7) & 64 & Male & Pleura & $\mathrm{MCN}$ & $\begin{array}{l}\text { Prescription of } \\
\text { a diuretic and } \\
\text { anticoagulant }\end{array}$ & $\begin{array}{l}\text { Died of } \\
\text { respiratory } \\
\text { failure }\end{array}$ \\
\hline Bacchetta et al (8) & 63 & Male & $\begin{array}{l}\text { Tunica } \\
\text { vaginalis } \\
\text { testis }\end{array}$ & $\mathrm{MCN}$ & $\begin{array}{l}\text { Prednisolone + } \\
\text { cisplatin + } \\
\text { pemetrexed + } \\
\text { radiotherapy }\end{array}$ & $\begin{array}{l}\text { Died of } \\
\text { disease } \\
\text { progression }\end{array}$ \\
\hline Farmer and Goldsmith (9) & 66 & Male & $\begin{array}{l}\text { Pleura, } \\
\text { pericardium, } \\
\text { brain }\end{array}$ & $\mathrm{MCN}$ & Prednisolone & $\begin{array}{l}\text { Died of } \\
\text { respiratory + } \\
\text { circulatory } \\
\text { failure }\end{array}$ \\
\hline
\end{tabular}

MCN, minimal-change nephropathy; MN, membranous nephropathy; MPG, mesangial proliferative glomerulonephritis.

bodies. On immunohistochemical examination, CK19, CD5, CR, HBME-1, Ki-67, WT-1 and CK5/6 were positive, whereas TTF-1 and CEA were negative (Fig. 2).

The patient was diagnosed with pleural mesothelioma associated with membranous nephropathy. Pemetrexed and cisplatin combination chemotherapy was administered (pemetrexed $850 \mathrm{mg}$ with cisplatin $60 \mathrm{mg}$, once per month). After the first cycle of chemotherapy, the urine protein was reduced to $1+$ on urine routine tests. However, the patient developed myelosuppression and did not receive the second cycle of chemotherapy in time; the 24-h urine total protein increased to $13.78 \mathrm{~g}$. After 5 months, the patient was in a stable condition and received the second cycle of chemotherapy. However, pemetrexed and cisplatin-induced myelosuppression developed again and the patient succumbed to the disease 2 weeks after the second cycle due to extensive dissemination and severe infection.

Written informed consent was obtained from the patient's family for the publication of the case details.

\section{Discussion}

In the present case, the patient's first clinical manifestation was nephrotic syndrome. The result of renal biopsy result was membranous nephropathy stage I, and the anti-PLA2R antibody was negative; 4 years later, he was diagnosed with
MPM and the proteinuria was aggravated with the progression of the MPM. The patient was diagnosed with membranous nephropathy associated with MPM. Furthermore, membranous nephropathy secondary to MPM is possible; membranous nephropathy may be idiopathic or secondary, with the common causes of the secondary type being infection, systemic lupus erythematosus, malignancy or medication. Anti-PLA2R may be used for the differential diagnosis of idiopathic and secondary membranous nephropathy (2).

Mesothelioma is a tumor derived from mesothelial tissue, often involving the peritoneum, pleura and pericardium. Approximately $80 \%$ of pleural mesotheliomas have been linked to asbestos exposure. However, malignant mesothelioma and nephrotic syndrome have been less extensively investigated. A total of 7 cases of nephrotic syndrome associated with malignant mesothelioma have been reported in the English literature (3-9); the details of these 7 cases are listed in Table I.

Among the 7 cases reviewed, 6 had a history of asbestos exposure, 1 had a history of prolonged tobacco exposure and in only 1 case the renal pathology result indicated membranous nephropathy (the pleural mesothelioma was diagnosed on autopsy). In the present case, the patient did not have a history of asbestos or tobacco exposure; he had membranous nephropathy, was diagnosed with malignant mesothelioma by 
means of a pleural biopsy and received the treatment for both conditions.

The prognosis of patients with membranous nephropathy and MPM is poor and the patients usually succumb to the cancer. The current treatment of MPM is multimodality therapy, including surgical resection, radiation therapy, chemotherapy and immunotherapy. The combination of cisplatin and pemetrexed is used as first-line treatment for MPM. Compared with cisplatin alone, combination chemotherapy was shown to improve the median survival from 9.3 to 12.1 months $(10,11)$. In our case, the patient received treatment with pemetrexed and cisplatin; however, he only received one cycle of chemotherapy and finally succumbed to the disease 6 months after the first cycle.

In summary, we herein present a case of membranous nephropathy associated with MPM. Based on the diagnosis and treatment of this case, we hypothesize that there are certain correlations between malignant mesothelioma and membranous nephropathy. Thus, when a patient is diagnosed with membranous nephropathy, secondary factors must be excluded.

\section{References}

1. Scherpereel A, Astoul P, Baas P, Berghmans T, Clayson H, de Vuyst P, Dienemann H, Galateau-Salle F, Hennequin C, Hillerdal G, et al: Guidelines of the European Respiratory Society and the European Society of Thoracic Surgeons for the management of malignant pleural mesothelioma. Eur Respir J 35: 479-495, 2010.
2. Santos FR: Membranous glomerulonephritis: New insights in pathophysiology and therapeutic approach. J Bras Nefrol 36: 59-62, 2014 (In Portuguese).

3. Schroeter NJ, Rushing DA, Parker JP and Beltaos E: Minimal-change nephrotic syndrome associated with malignant mesothelioma. Arch Intern Med 146: 1834-1836, 1986.

4. Tanaka S, Oda H, Satta H, Takizawa T, Tochikubo O, Takagi N, Ishii $\mathrm{M}$ and Kaneko T: Nephrotic syndrome associated with malignant mesothelioma. Nephron 67: 510-511, 1994.

5. Dogan M, Ozal G, Savas B, Gungor M, Utkan G, Yalcin B and Icli F: Malign peritoneal mesothelioma with nephrotic syndrome. Bratisl Lek Listy 113: 43-45, 2012.

6. Galesic K, Bozic B, Heinzl R, Scukanec-Spoljar M and Bozikov V: Pleural mesothelioma and membranous nephropathy. Nephron 84: 71-74, 2000.

7. Suzuki S, Toyoshima M, Nihashi F, Tsukui H, Baba S, Sugimura H and Suda T: An autopsy case of malignant pleural mesothelioma associated with nephrotic syndrome. Intern Med 53: 243-246, 2014.

8. Bacchetta J, Ranchère D, Dijoud F and Droz JP: Mesothelioma of the testis and nephrotic syndrome: A case report. J Med Case Rep 3: 7248, 2009.

9. Farmer CK and Goldsmith DJ: Nephrotic syndrome and mesenteric infarction secondary to metastatic mesothelioma. Postgrad Med J 77: 333-334, 2001.

10. van Zandwijk N, Clarke C, Henderson D, Musk AW, Fong K, Nowak A, Loneragan R, McCaughan B, Boyer M, Feigen M, et al: Guidelines for the diagnosis and treatment of malignant pleural mesothelioma. J Thorac Dis 5: E254-E307, 2013.

11. Vogelzang NJ, Rusthoven JJ, Symanowski J,Denham C, Kaukel E, Ruffie P, Gatzemeier U, Boyer M, Emri S, Manegold C, et al: Phase III study of pemetrexed in combination with cisplatin versus cisplatin alone in patients with malignant pleural mesothelioma. J Clin Oncol 21: 2636-2644, 2003. 